\title{
Brown Tumor of Tertiary Hyperparathyroidism in Chronic Hemodialysis: A Case Report
}

Labrassi $\mathrm{M}^{1 *}$, Chettati $\mathrm{M}^{2}$, Anibar $\mathrm{S}^{3}$, Shabi I ${ }^{4}$, Fadili $\mathrm{W}^{5}$, Laouad I

${ }^{-6}$ Service de néphrologie d'hémodialyse et de transplantation rénale CHU Med IV de Marrakech

DOI: $10.36347 /$ sjams.2021.v09i03.026

| Received: 23.02.2021 | Accepted: 08.03.2021 | Published: 18.03.2021

*Corresponding author: Labrassi Maryem

Abstract

Hyperparathyroidism is a disease characterized by excessive secretion of parathyroid hormone, the hormone responsible for calcium and phosphate homeostasis in the body. It can be of three types: primary, secondary, or tertiary. Secondary and tertiary hyperparathyroidism is a frequent complication of chronic kidney disease (CKD). The brown tumor is an unusual presentation of fibrous osteitis that represents a serious complication of renal osteodystrophy, affecting predominantly the hands, feet, skull, and facial bones. Case report: The aim of this paper is to describe the case of a 39-year-old female patient, with chronic kidney disease who has been on dialysis for 11 years and developed severe tertiary hyper- parathyroidism, brown tumor of the face, that has caused constant pain, malocclusion and deformation facial, and diffuse osteopathy with bone squelet deformation and thoracic deformation, in whom the treatment consisted of parathyroidectomy. Despite the normalization of serum parathyroid hormone and alkaline phosphates, tumor regression was slow and patient's important functional and esthetic deficits persisted. The prevention and treatment of secondary and tertiary hyperparathyroidism remains a permanent challenge for nephrologist. The brown tumor of the face is a severe complication of early hyperparathyroidism hence the interest of screening and treating patients with especially chronic hemodialys.

Keywords: Hemodialysis patient, brown tumor, hyperparathyroidism, phosphocalcic metabolism, renal osteodystrophy.

Copyright $\odot 2021$ The Author(s): This is an open-access article distributed under the terms of the Creative Commons Attribution 4.0 International License (CC BY-NC 4.0) which permits unrestricted use, distribution, and reproduction in any medium for non-commercial use provided the original author and source are credited.

\section{INTRODUCTION}

Brown tumor (BT) of hyperparathyroidism (HPT) is a focal bone lesion caused by increased osteoclastic activity [1-3] and fibroblast proliferation encountered in primary and, more rarely, in secondary HPT [1, 2, 4, 5]. However, it has also been described as a manifestation of calcium malabsorption and some forms of osteomalacia $[1,2]$.

Since dialysis has become more readily available, an in- crease in the number of patients with renal osteodystrophy can be anticipated.

Secondary HPT (SHPT) associated with CKD often causes fibrous osteitis, especially in the spine, ribs, hands, clavicle, long bones, and skull $[1,6]$.

In the craniofacial region, there are reports of tumors involving maxilla, palatine bone, temporal, nasal, orbit, and paranasal sinuses. These tumors are more common in the mandible than in the maxilla, and are three times more common in women (over 50 years) than men. BT can cause single or multiple lesions. They are usually isolated, lytic, expansive, lesions that stimulate bone destruction $[5,7]$.

Initial treatment should include control of HPT through normalization of serum calcium and phosphate, to enable a gradual tumor regression, with or without parathyroidectomy (PTx) [8].

BT in hemodialysis patients is currently poorly observed, because of, in one hand, the regular biological examinations that allow the diagnosis of SHPT before this onset, and in the other hand, to new treatments: non-calcium chelators of phosphorus, vitamin $\mathrm{D}$ and calcimimetics [9]. Unfortunately, this therapeutic arsenal, in addition to the fact that its superiority has not been proven with respect to calcium intake alone (no loss of parathyroid hormone [PTH] with non-calcium chelators of phosphorus and risk of hypocalcemia with calcimimetics), is not available in its entirety in our country and we continue to observe cases of TB in our hemodialysis patients [10]. 
Thus, the purpose of this case report is to present and discuss the course and treatment of a brown tumor in oral maxillofacial in HD patient with and tertiary hyperparathyroidism [8].

\section{Case Report}

A 39 -year old woman on chronic hemodialysis was refereed in our departement with painful swelling of multiple facial, legs, knees and hands bones. She reported that 18 months before this symptomatology, she had bone pain in the lower limbs with paraparesis, subsequently aggraved by paraplegia. She noticed swelling of the mandibule that continued to increase in size and caused constant pain, malocclusion and deformation facial, thoracic and deformation of the bone squelet. A painless mass in the neck region around the thyroid cartilage level was noted 2 years previously (Figure 1).

Laboratory tests revealed an elevated serum calcium level of $106 \mathrm{mg} / \mathrm{L}$ and a hight phosphorus level of $64 \mathrm{mg} / \mathrm{l}$. The serum alkaline phosphatase concentration was 2408 IU/L. Subsequent examination revealed a parathyroid hormone (PTH) level of $2070 \mathrm{pg} / \mathrm{Ml}$, aluminium level was 0,37 umol/l.

The lumbar dorso scanner showed diffuse osteopathy, condensing bone lesions and geodesic osteolysis and diffuse vertebral areas interest the body and posterior arch without abnormality of the perirachidian soft tissues (figure 2). The facial scanner showed osteodystrophy with fibrous dysplasia (figure $3)$.

Parathyroid scintigraphy: presence of a bulky tissue nodule opposite the lower pole of the left thyroid lobe intensively fixing the radiotracer compatible with a parathyroid origin: adenoma ,nodule under right lobar, Abnormal uptake of maxillary bones, whose TEMPTDM fusion images favor highly evolved brown tumors (figure 3).

Thus, a parathyroidectomy (PTX) was performed in June 2019 aimed to normalizing serum PTH, calcium, alkaline phosphatase, and restraining the spread of the tumor. However, despite the reduced levels of PTH, calcium, phosphor and alkaline phosphatase, the tumor has not regressed, resulting in severe morphological and functional deficits to the patient.

\section{DisCUSSION}

BT of hyperparathyroidism is usually regarded as a benign neoplastic process $[1,2,11,12,13]$. It has an incidence of 3 to $4 \%$ in patients with primary HPT and $1.5 \%$ in those with secondary HPT. This rate tends to increase with the increased survival of patients with chronic renal failure $[14,12,15]$. BT can occur in several body regions, affecting predominantly the hands, feet, skull, clavicle, ribs, pelvis, femur, and facial bones $[7,13]$. It is more frequent in the mandible than in the maxilla, more prevalent in individuals aged 50 years or over and is three times more common in women than men $[3,4,11,12]$.

In another study, the average age was 36.1 years (17-67 years) at the time of diagnosis, with a sex ratio of $0.6[10]$. Clinical symptomatology is dominated by bone pain and palpable masses $[16,17]$. The main tumoral localities are cost, sternum, clavicle, pelvis and long bone diaphysis [18, 19]. Achievement of the mandible and maxillary sinuses is less common, reported in $4 \%$ of cases [20,21]. Spinal involvement is rarer; it can be found with or without associated neurological signs $[18,22,23]$.Concurring with the literature, the case shows a female patient, 53-year-old female patient with brown tumor affecting exclusively the maxilla and the mandible [8].

In most cases, the tumors are asymptomatic and do not require specific treatment [7, 15]. However, they may cause pathological fractures, compression of the spinal cord, involving the spine, and when they affect the face they may cause deformity, respiratory distress, and dysphagia [7, 12]. Facial asymmetry and paresthesia, of the lower lip (left side) are the most marked features. Also, the area was painless and palpation revealed that the mass was firm, in the case reported [8].

The diagnosis of BT of hyperparathyroidism can be suggested by pathological examination. However, it may not provide conclusive evidence to distinguish it from similar lesions [12]. The differential diagnosis must be made between central giant cell granuloma, aneurysmal bone cyst, cherubism, and Paget's disease [3, 12]. Clinical and chemical analysis of patient's tissues is also useful in the differentiation between these conditions $[11,14,15]$. Some alterations in the serum levels of calcium, phosphorus, and PTH indicate HPT, determining brown tumor of hyperparathyroidism as the most likely diagnosis [13, 15]. Laboratory tests performed prior to PTx indicated HPT, balanced following the referred surgical procedure. In view of the above mentioned, the other pathologies were discarded and BT was the main diagnostic hypothesis.

Radiographically, the brown tumors of hyperparathy- roidism have well-defined margins, and may cause expan- sion of cortex and fracture $[5,12$, 15]. Medullar deminer- alization of the mandible and the loss of the lamina dura around the tooth root may be useful in the differential diagnosis because these alterations are associated to hyperparathyroidism [5, 13, 15], and remineralization trig- gered after the normalization of the serum levels of bone alkaline phosphatase and PTH $[4,15]$. This change in the profile of the lesion was clearly observed during the course of 
Labrassi M et al; Sch J App Med Sci, Mar, 2021; 9(3): 428-432

the disease: an osteolytic lesion was first ob- served with expansion and perforation of the cortex, and, subsequently, after the PTx and standardization of serum level of PTH and alkaline phosphatase, there was a change in the profile of the injury, assuming a homoge- neous ground-glass appearance.

The first step in the treatment is the surgical exeresis and enucleation and reconstruction, besides, in many cases, total regression of the tumor is not possible because of its large size, in such cases, neoadjuvant radiotherapy to reduce tumor volume may be proposed.in somes cases specially when tumor volume is important, radiotherapy neoadjuvant may preceded the sururgy $[24,8,25,26]$. In cases of very large lesions that require extensive resections, reconstructions with bone grafts are necessary [24].

The medical treatment to control HTP, calcium and phosphorus levels was be used in some case, but many of them show increas or maintenance of the tumor sizes even after parathyroidectomy [8].

\section{Conclusion}

The prevention and treatment of SHPT and THPT remains a permanent challenge for the nephrologist. BT is a rare and severe form of HPTS. Treatment is progressing thanks to an understanding of the physiopathological mechanisms involved in the development of HPTS. Generally, the brown tumor evolves towards the spontaneous clinical and radiological regression, after the control of the hyperparathyroidism, the surgical excision of the BT is indicated only before an abnormal increase of the tumoral volume or a too slow regression with functional disorders.

The peculiarities of our case are that it reports one of the most important series of published BT and is characterized by the multifocal nature of these tumors.

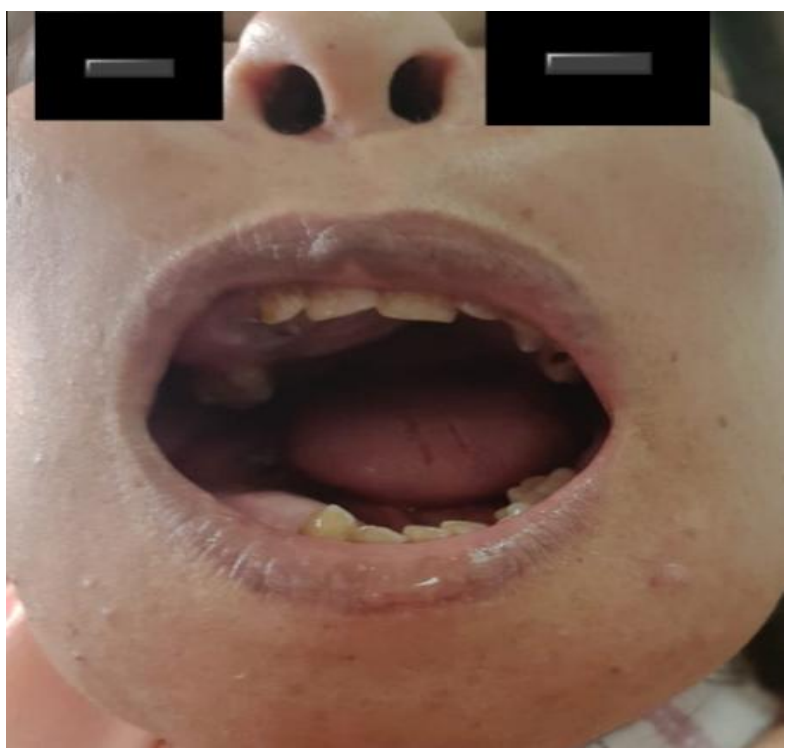

Fig-1: Face deformation because of brown tumor
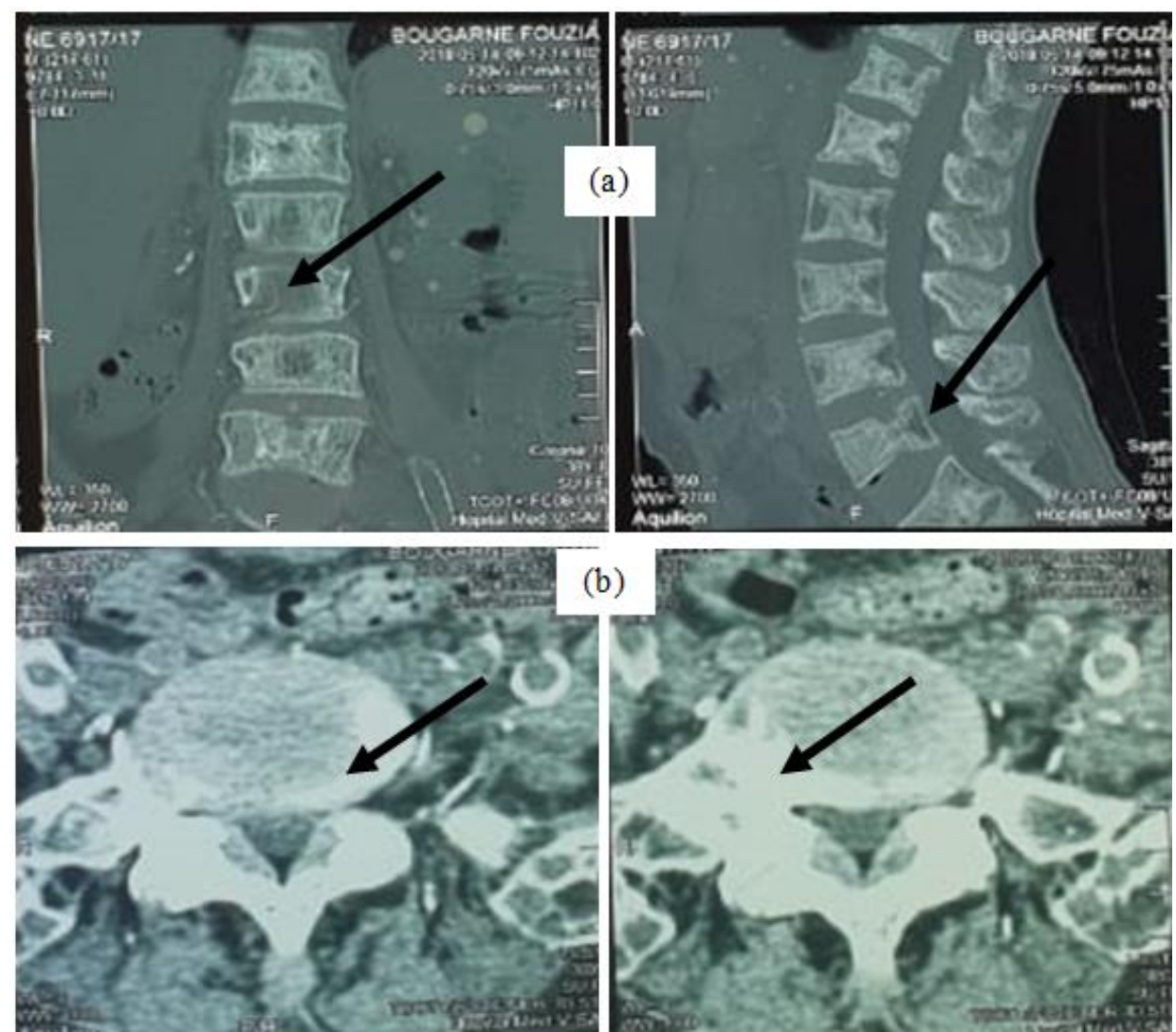

(b)

Fig-2: (a) Blowing and condensing lesion of the spine (b) Lytic and condensing lesion of the posterior arch 


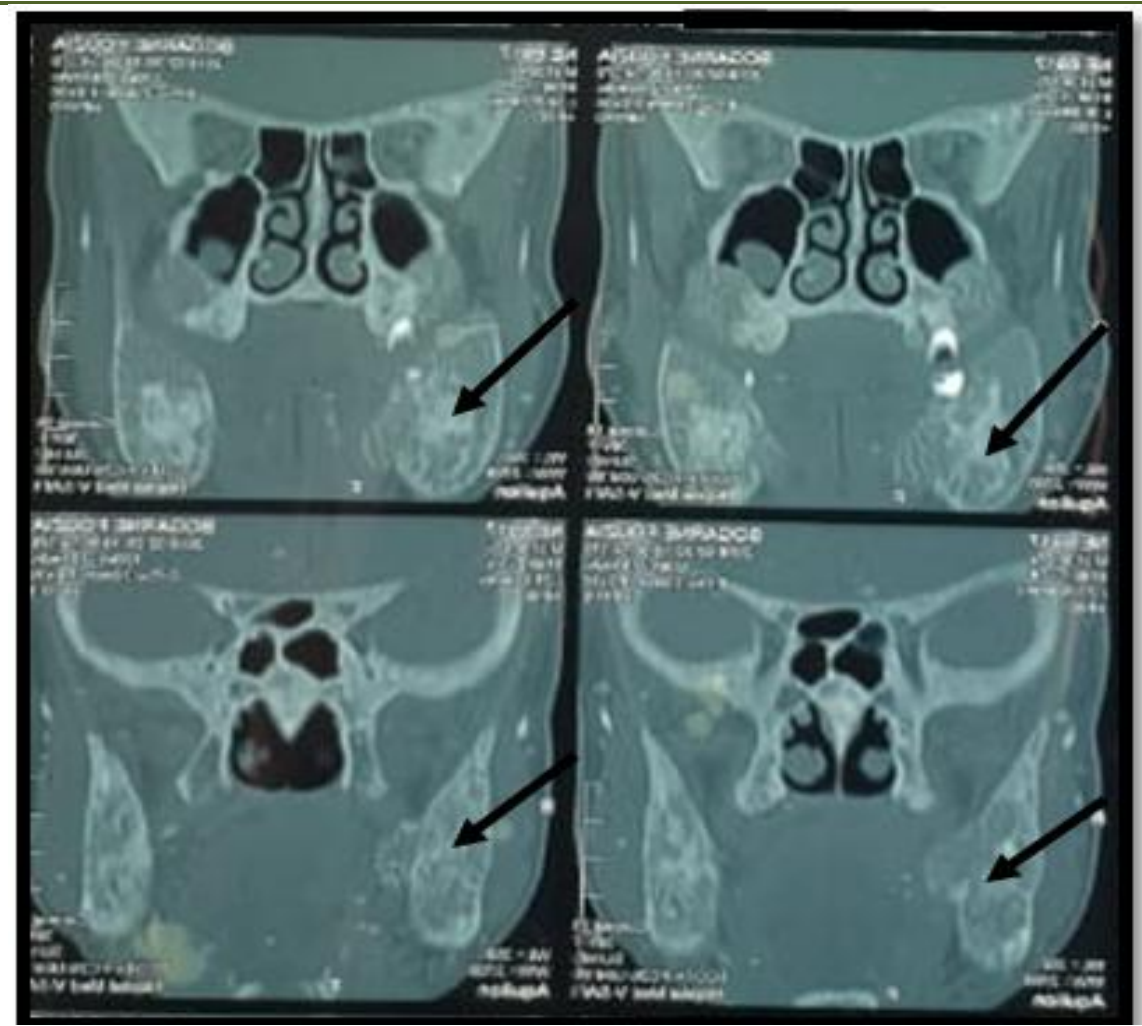

Fig-3: Blowing and condensing lesion of the face

\section{REFERENCES}

1. Nabi Z, Algailani M, Abdelsalam M, Asaad L, Albaqumi M. Regression of brown tumor of the maxilla in a patient with second- ary hyperparathyroidism after a parathyroidectomy. Hemodial Int. 2010; 14:247-249

2. Mateo L, Massuet A, Solà M, Pérez Andrés R, Musulen E, Sánchez Torres MC. Brown tumor of the cervical spine: a case report and review of the literature. Clin Rheumatol 30:419-424 hyperparathyroidism after a parathyroidectomy. Hemodial Int.2011; 14:247-249

3. Selvi F, Cakarer S, Tanakol R, Guler SD, Keskin C. Brown tumour of the maxilla and mandible: a rare complication of tertiary hyperparathyroidism. Dentomaxillofac Radiol. 2009; 38:53-58

4. Nunes TB, Bologna SB, Witzel AL, Nico MMS, Lourenço SV. A rare case of concomitant maxilla and mandible brown tumours, papillary thyroid carcinoma, parathyroid adenoma, and osteitis fibrosa cystica. Case Rep Dent; 2016.

5. Verma P, Verma KG, Verma D, Patwardhan N. Craniofacial brown tumor as a result of secondary hyperparathyroidism in chron- ic renal disease patient: a rare entity. J Oral Maxillofac Pathol. 2014; 18(2): 267-270.

6. Fatma LB, Barbouch S, Fethi BH, Imen BA, Karima K, Imed H, Fethi el Y, Fatma BM, Rim G, Taieb BA, Maiz HB, Adel K. Brown tumor in patients with renal failure and secondary hyperparathyroidism: report of 12 cases. Saudi J Kidney Dis Transpl. 2010; 21(4):772-777
7. Leal CTS, Lacativa PGS, Gomes EMS, Nunes RC, Costa FLFDS, Gandelmann IHA. Surgical approach and clinical out- come of a deforming brown tumour at the maxilla in a patient with secondary hyperparathyroidism due to chronic renal failure. Arq Bras Endocrinol Metab. 2006; 50(5):963-967

8. Isaac Vieira Queiroz 1 \& Samara Pereira Queiroz 1 \& Rui Medeiros Jr. 2 Rodolfo Bonfim Ribeiro 1 \& Iêda Margarida Crusoé-Rebello 1 \& Jair Carneiro Leão 2 DOI 10.1007/s10006-016-0575-0

9. Ballinger AE, Palmer SC, Nistor I, Craig JC, Strippoli GF. Calcimimetics for secondary hyperparathyroidism in chronic kidney disease patients. Cochrane Database Syst Rev. 2014; 12:CD006254.

10. Imen Gorsane $a^{*}, b, c$, Asma Zammouri a, b, Jihede El Meddeb a, b, Fathi Younsi a,b, Ahlem Bartkiz b,d, Jouida Abdelmoula b,d, Samia Barbouch a,b, Taieb Ben Abdallah a, b, c

11. Proimos E, Chimona TS, Tamiolakis D, Tzanakakis MG, Papadakis CE. Brown tumor of the maxillary sinus in a patient with primary hyperparathyroidism: a case report. J Med Case Rep.2009 ; 3:7495.

12. Nicola Di Daniele, Stefano Condò, Michele Ferrannini, Marta Bertoli, Valentina Rovella, Laura Di Renzo, Antonino De Lorenzo, "Brown Tumour in a Patient with Secondary Hyperparathyroidism Resistant to Medical Therapy: Case Report on Successful Treatment after Subtotal Parathyroidectomy", International Journal of Endocrinology. 2009, Article 
Labrassi M et al; Sch J App Med Sci, Mar, 2021; 9(3): 428-432

13. Jafari-Pozve N, Ataie-Khorasgani M, Jafari-Pozve S, Ataie- Khorasgani M. Maxillofacial brown tumors in secondary hyperparathyroidism: a case report and literature review. J Res Med Sci. 2014; 19(11):1099-1102

14. Qaisi M, Loeb M, Montague L, Caloss R. Mandibular brown tumor of secondary hyperparathyroidism requiring extensive resection: a forgotten entity in the developed world? Case Reports in Medicine; 2015.

15. Takeshita T, Tanaka H, Harasawa A, Kaminaga T, Imamura T, Furui S. Brown tumor of the sphenoid sinus in a patient with secondary hyperparathyroidism: CT and MR imaging findings. Radiat Med2004; 22(4):265-268

16. Li K, Chen Z, Zhao X, Zhou Y, Zhang D, Yang G. Secondary hyperparathy- roidism associated with multiple brown tumor: a case report. J Med Coll PLA. 2011; 26:360-6.

17. Triantafillidou K, Zouloumis L, Karakinaris G, Kalimeras E, Iordanidis F. Brown tumors of the jaws associated with primary or secondary hyperparathyroid- ism. A clinical study and review of the literature. Am J Otolaryngology. 2006; 27:281-6.

18. Tarrass F, Ayad A, Benjelloun M, Anabi A, Ramdani B, Benghanem MG. Cauda equina compression revealing brown tumor of the spine in a long-term hemodialysis patient. Joint Bone Spine. 2006; 73:748-50.

19. Joyce J, Idea RJ, Grossman SJ, Liss RG, Lyons JB. Multiple brown tumors in unsuspected primary hyperparathyroidism mimicking metastatic disease on radiogragh and bone scan. Clin Nucl Med. 1994;19:630-5.

20. Lerman MA, Do C, Gunaratnam L, Kulkarni C, and Tucker K, Woo SB. Localized mandibular enlargement in end-stage renal disease: two case reports and a review of the literature. Oral Surg Oral Med Oral Pathol Oral Radiol. 2012; 113:384-90.

21. Tarrass F, Benjelloun M, Bensaha T. Severe jaw enlagement associated with uremic. Hemodial Int. 2008;12:16-8.

22. Azria A, Beaudreuill J, Juque JP, Quillard A, Bardin T. Tumeur brune rachidienne re' ve' latrice d'une hyperparathyrö"die secondaire : a' propos d'un cas. Rev Rhum. 2000;67:232-6.

23. Fargen KM, Lin CS, Jeung JA, Yachnis AT, Jacob RP, Velat GJ. Vertebral brown tumors causing neurologic compromise. World Neurosurg. 2013; 79:208-16.

24. Lajolo C, Patini R, Limongelli L, Favia G, Tempesta A, Contaldo M, De Corso E and Giuliani M. Brown tumors of the oral cavity: presentation of 4 new cases and a systematic literature review. Oral surgery, oral medicine, oral pathology and oral radiology. 2020; 129(6), 575584.e4.

25. DOS Santos, Bethina Koth, Valesca Sander, Figueiredo, Maria Antonia. Brown tumor of the jaws as a manifestation of tertiary hyperparathyroidism: A literature review and case report. Special Care in Dentistry. 2018, 38(3): 163-171.

26. Suruchi K Gupta, MD, Runhua Hou, MD, Harold Rosen, MD, SAT-364 Brown Tumor of the Mandible in Severe Uncontrolled Primary Hyperparathyroidism, Journal of the Endocrine Society, Volume 4, Issue Supplement_1, AprilMay; 2020, SAT364, https://doi.org/10.1210/jendso/bvaa046.379. 